\title{
Determinan Manajemen Laba Perusahaan di Sektor Konsumsi
}

\author{
Muhammad Fajri \\ Universitas Islam 45 Bekasi \\ Jl. Cut Mutia N0. 83 Kota Bekasi, Jawa Barat. 17113 \\ Correspondence e-mail : muhammadfajeriii16@gmail.com
}

\begin{abstract}
The aim of this research is to provide empirical evidence on the impact of good corporate governance, free cash flow, and leverage ratio on earnings management. Good corporate governance is measured by audit committee's size, the proportion of independent commissioners, institutional ownership, and managerial ownership. Discretionary accrual is the proxy of earning management. This research used 28 consumer goods companies listed in Indonesia Stock Exchange from 2016 to 2018 . Data were analyzed using panel data with random effect model. Based on the result of analysis concluded that all components of good corporate governance (audit committee's size, the proportion of independent commissioners, institutional ownership, and managerial ownership), have no significant effect on earnings management, on other hand leverage ratio has a negative effect and no significant on earning management, and free cash flow has a positve and no significant effect on earnings management
\end{abstract}

Keywords : Earnings Management; Good Corporate Governance; Free Cash Flow; Leverage Ratio.

\section{PENDAHULUAN}

Informasi kondisi dan kinerja sebuah perusahaan tidak hanya diperlukan pihak internal, namun juga diperlukan pihak eksternal. Bagi pihak eksternal informasi sebuah perusahaan didapatkan dari laporan keuangan. Didalam laporan keuangan terdapat informasi tentang laba perusahaan. Tujuan informasi laba untuk melihat kinerja atau prestasi manajemen. Ditambahkan lagi bahwa informasi laba digunakan investor atau pihak lain yang berkepentingan sebagai indikator efisiensi penggunaan dana yg tertanam dalam perusahaan yang diwujudkan dalam tingkat pengembalian dan indikator untuk kenaikan kemakmuran (Ghozali dan Chariri, 2007). Adanya asimetri informasi dan kecenderungan dari pihak eksternal (investor) untuk lebih memperhatikan informasi laba sebagai parameter kinerja perusahaan, akan mendorong manajemen untuk melakukan manipulasi dalam menunjukkan informasi laba, yang disebut sebagai manajemen laba (earnings management). Beberapa faktor yang dapat mempengaruhi praktek manajemen laba dalam perusahaan adalah praktek good corporate governance, kebijakan free cash flow dan leverage ratio. Terdapat perbedaan hasil penelitian faktor-faktor tersebut dalam mempengaruhi praktek manajemen laba perusahaan.

Berdasarkan beberapa teori yang mengindikasikan free cash flow sebagai salah satu faktor yang dapat mempengaruhi adanya praktik manajemen laba serta pentingnya penerapan good corporate governance dan peranan auditor dalam meminimalisasi dan mendeteksi manajemen laba. Manajemen laba bisa menjadi salah satu faktor yang dapat mengurangi kredibilitas laporan keuangan karena angka yang dilaporkan tersebut tidak mencerminkan kondisi sebenarnya. Perilaku manajer yang melakukan manajemen laba dapat diminimalisir dengan menerapkan good corporate governance. Manajemen laba merupakan keputusan dari manajer untuk memilih kebijakan akuntansi tertentu yang dianggap bisa mencapai tujuan yang diinginkan, baik itu untuk meningkatkan laba atau mengurangi tingkat kerugian yang dilaporkan (Scott, 2011). Menurut Scott (2011) beberapa motivasi yang mendorong manajemen melakukan earning management, antara lain adalah (1) Motivasi bonus, yaitu manajer akan berusaha mengatur laba bersih agar dapat memaksimalkan bonusnya; (2) Hipotesis perjanjian hutang (Debt Covenant Hypothesis), berkaitan dengan persyaratan perjanjian hutang yang harus dipenuhi, laba yang tinggi diharapkan dapat mengurangi kemungkinan terjadinya pelanggaran syarat perjanjian hutang; (3) Meet Investors Earnings Expectations and Maintain Reputation, perusahaan yang melaporkan laba lebih besar daripada ekspektasi investor harga sahamnya akan mengalami peningkatan yang signifikan karena investor memprediksi perusahaan akan mempunyai masa depan yang lebih baik; (4) IPO (Initial Public Offering), manajer perusahaan yang akan go public termotivasi untuk melakukan manajemen laba sehingga laba yang dilaporkan menjadi tinggi dengan harapan dapat menaikkan harga saham perusahaan.

Sebuah perusahaan memiliki kemungkinan yang besar dalam melakukan manajemen laba jika free cash flow yang dimiliki tinggi. Hal ini dikarenakan perusahaan tersebut terindikasi menghadapi masalah 
keagenan yang lebih besar (Chung et al., 2005). Penelitian sebelumnya menunjukkan bahwa perusahaan dengan surplus arus kas bebas yang tinggi juga cenderung melakukan praktik manajemen laba dengan meningkatkan laba yang dilaporkan untuk menutupi tindakan pihak manajer yang tidak optimal dalam memanfaatkan kekayaan perusahaan. Investor untuk melihat kemampuan dan resiko perusahaan, salah satunya dengan leverage rasio. Penggunaan debt to asset ratio sebagai proksi variabel leverage ratio. Perusahaan yang memiliki rasio hutang relatif tinggi akan memiliki ekspektasi pengembalian yang juga lebih tinggi ketika perekonomian berada pada kondisi yang normal, namun memiliki resiko kerugian ketika ekonomi mengalami resesi (Brigham dan Houston, 2010). Dengan memperoleh dana melalui hutang, para pemegang saham dapat mempertahankan kendali mereka atas perusahaan tersebut dengan sekaligus membatasi investasi yang mereka tanamkan.

Berdasarkan latar belakang di atas maka perlu penelitian yang lebih dalam tentang pengaruh apakah ukuran komite, audit proporsi dewan komisaris, independen kepemilikan institusional, kepemilikan manajerial, free cash flow dan leverage ratio berpengaruh terhadap manajemen laba. Hasil penelitian akan memberikan bukti empiris pengaruh ukuran komite, audit proporsi dewan komisaris, independen kepemilikan institusional, kepemilikan manajerial, free cash flow dan leverage ratio terhadap manajemen laba. Ditambahkan lagi bahwa hasil penelitian ini diharapkan dapat memberikan informasi yang bermanfaat untuk meningkatkan penerapan good corporate governance, free cash flow, dan leverage ratio dalam rangka pengelolaan perusahaan, terutama yang terkait dengan usaha meminimalkan praktik manajemen laba.

\section{METODE PENELITIAN}

Penelitian ini merupakan penelitian kuantitatif. Variabel independen dalam penelitian ini adalah Ukuran Komite Audit, Proporsi Dewan Komisaris Independen, Kepemilikan Institusional, Kepemilikan Manajerial, Free Cash Ratio, dan Leverage Ratio. Sedangkan variabel dependen adalah manajerial laba yang diproksikan dengan discretionary accruals.

Tabel 1

Definisi dan Operasional Variabel

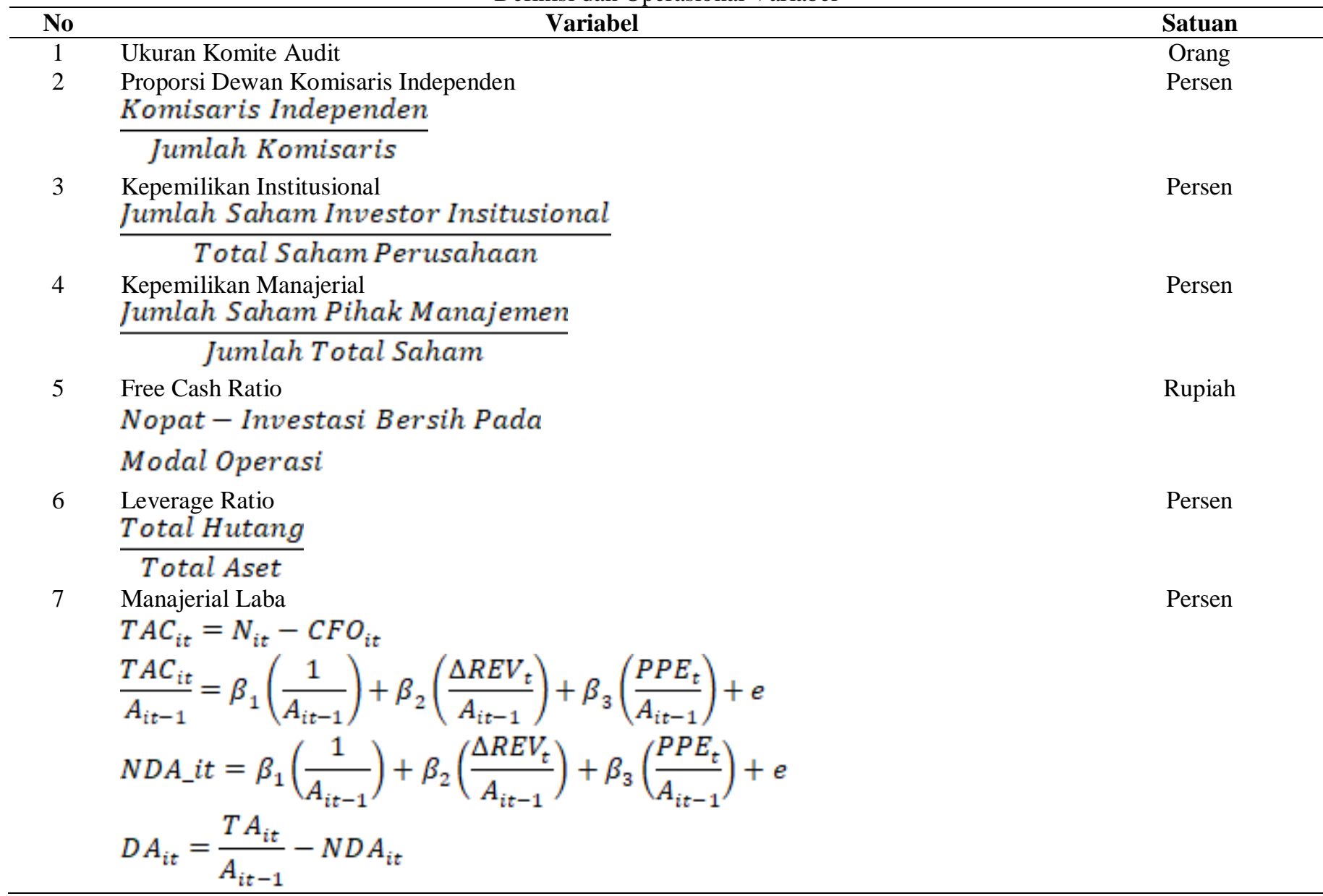




\section{Teknik Pengumpulan Data}

Data yang digunakan dalam penelitian ini merupakan data sekunder dengan bentuk data panel. Data dikumpulkan dari laporan keuangan perusahaan yang tercatat di Bursa Efek Indonesia (BEI) periode 2016 sampai 2018. Populasi dalam penelitian ini adalah perusahaan di sektor industri barang konsumsi yang tercatat papan Utama BEI. Data panel merupakan data kombinasi antara individu (cross-section) dan runtun waktu (time series). Terdapat 28 perusahaan sebagai unit cross-section dan periode 2016 sampai 2018 sebagai unit time-series.

Tabel 2

Perusahaan di Sektor Industri Barang Konsumsi

\begin{tabular}{|c|c|c|}
\hline No & Kode Saham & Nama Perusahaan \\
\hline 1 & AISA & Tiga Pilar Sejahtera Food Tbk. \\
\hline 2 & ALTO & Tri Banyan Tirta Tbk. \\
\hline 3 & BUDI & Budi Starch \& Sweetener Tbk. \\
\hline 4 & CEKA & Wilmar Cahaya Indonesia Tbk. \\
\hline 5 & DLTA & Delta Djakarta Tbk. \\
\hline 6 & DVLA & Darya-Varia Laboratoria Tbk. \\
\hline 7 & GGRM & Gudang Garam Tbk. \\
\hline 8 & GOOD & Garudafood Putra Purrijaya Tb \\
\hline 9 & HMSP & H.M. Sampoerna Tbk. \\
\hline 10 & HOKI & Buyung Poetra Sembada Tbk. \\
\hline 11 & ICBP & Indofood CBP Sukses Makmur Tbk \\
\hline 12 & INAF & Indofarma (Persero) Tbk. \\
\hline 13 & INDF & Indofood Sukses Makmur Tbk. \\
\hline 14 & KAEF & Kimia Farma (Persero) Tbk. \\
\hline 15 & KICI & Kedaung Indah Can Tbk \\
\hline 16 & KLBF & Kalbe Farma Tbk. \\
\hline 17 & MBTO & Martina Berto Tbk. \\
\hline 18 & MLBI & Multi Bintang Indonesia Tbk. \\
\hline 19 & MRAT & Mustika Ratu Tbk. \\
\hline 20 & MYOR & Mayora lndah Tbk. \\
\hline 21 & RMBA & Bentoel lnternasiona1 lnvestam \\
\hline 22 & ROTI & Nippon lndosari Corpindo Tbk. \\
\hline 23 & SIDO & lndustri Jamu dan Farmasi Sido \\
\hline 24 & TCID & Mandom Indonesia Tbk. \\
\hline 25 & TSPC & Tempo Scan Pacific Tbk. \\
\hline 26 & ULTJ & Ultra Jaya Milk Industry \& Tra \\
\hline 27 & UNVR & Unilever Indonesia Tbk. \\
\hline 28 & WIIM & Wismilak Inti Makmur Tbk. \\
\hline
\end{tabular}

Sumber : Bursa Efek Jakarta (BEI) www.idx.co.id

\section{Teknik Analisis}

Analisis dalam penelitian ini menggunakan pendekatan ekonometrika dengan regresi data panel untuk membuktikan faktor - faktor yang mempengaruhi manajemen laba. Persamaan regresi nya sebagai berikut : $D A_{i t}=\beta_{0}+\beta_{1} U K A_{i t}+\beta_{2} D K I_{i t}+\beta_{3} K I_{i t}+\beta_{4} K M_{i t}+\beta_{5} F C F_{i t}+\beta_{6} L E V_{i t}+e$

dimana; DA $=$ discretionary accruals $;$ UKA = Ukuran Komite Audit; DKI = proporsi dewan komisaris independen; $\mathrm{KI}=$ kepemilikan institusional; $\mathrm{KM}=$ kepemilikan manajerial; $\mathrm{FCF}=$ free cash flow; $\mathrm{LEV}=$ leverage ration; $\beta_{0}=$ konstanta; $\beta_{1}, \beta_{2}, \beta_{3}, \beta_{4}, \beta_{5}, \beta_{6}=$ Koefisien regresi dari variabel independen.

Terdapat dua model dasar pada data panel yaitu; fixed effect dan random effect model (Verbeek, 2008).

\section{Fixed Effect Model}

Permasalahan yang terdapat pada data panel dengan asumsi intersep dan slope inkonsisten. Inkonsisten data panel tersebut bisa diselesaikan dengan manambahkan variabel dummy. Penggunaan variabel dummy ditujukan untuk terjadinya perbedaan nilai parameter yang berbeda-beda baik dari unit cross-section maupun dari time-series. Pendekatan dengan menambahkan variabel dummy ini disebut Least Square Dummy Variable (LSDV), dengan persamaan sebagai berikut: 


$$
y_{i t}=\alpha+\beta_{j} x_{i t}^{j}+\sum_{i=2}^{n} \alpha_{i} D_{i}+\varepsilon_{i t}
$$

dimana; $y$ adalah variabel dependen, $\alpha$ intersep yang yang berubah-ubah antar cross-section, $\beta_{j}$ adalah parameter untuk variabel ke-j, $x^{j}$ adalah variabel bebas $\mathrm{j}, \varepsilon$ adalah error term, $D$ adalah dummy variable, subcript $i$ adalah unit cross-section dan $t$ adalah unit time-series.

\section{Random Effect Model}

Data panel dengan pendekatan fixed effect terdapat kelemahan ketidakpastian karena adanya variable dummy. Penggunaan dummy variable akan mengurangi derajat bebas (degree of freedom) yang akhirnya akan mengurangi efisiensi dari parameter estimasi. Mengatasi kelemahan pada data tersebut digunakan pendekatan random effect. Random effect menggunakan residual yang diduga memiliki hubungan antar waktu dan antar individu. Model random effect mengasumsikan bahwa setiap individu memiliki perbedaan intersep yang merupakan variabel random. Persamaan pada model random effect dituliskan sebagai berikut :

$$
\begin{aligned}
& \hat{y}_{i t}=\alpha+\beta_{j} x_{i t}^{j}+\varepsilon_{i t} \\
& \varepsilon_{i t}=u_{i}+v_{t}+w_{i t}
\end{aligned}
$$

dimana; $u_{i} \sim N\left(0, \sigma_{u}^{2}\right)$ adalah komponen cross-section error, $v_{i} \sim N\left(0, \sigma_{v}^{2}\right)$ adalah komponen time series error, dan $\mathrm{w}_{\mathrm{i}} \sim N\left(0, \sigma_{\mathrm{w}}^{2}\right)$ adalah error time series dan cross-section.

Verbeek (2008) menyarankan dimana hipotesis null $x_{i t}$ dan $\alpha_{i}$ tidak terjadi korelasi atau biasa disebut Hausman test. Secara umum Hausman test membandingkan dua estimator yang konsisten di hipotesis null dan hipotesis alternatif sedangkan estimator lain hanya konsisten di hipotesis null saja. Misalkan $E\left\{\varepsilon_{i t} x_{i s}\right\}=0$ untuk semua $s, t$, maka fixed effect dengan estimator $\widehat{\beta}_{F E}$ adalah konsisten untuk $\beta$ tidak peduli $x_{i t}$ dan $\alpha_{i}$ tidak berkorelasi, sedangkan random effect estimator $\widehat{\beta}_{R E}$ adalah konsisten dan efisien hanya jika $x_{i t}$ dan $\alpha_{i}$ tidak berkorelasi. Secara umum, hal ini mengharuskan adanya estimasi kovarian antara $\widehat{\beta}_{F E}$ dan $\widehat{\beta}_{R E}$, tetapi karena estimator efisien di hipotesis $n u l l$, maka persamaannya adalah :

$$
V\left\{\hat{\beta}_{F E}-\hat{\beta}_{R E}\right\}=V\left\{\hat{\beta}_{F E}\right\}-V\left\{\hat{\beta}_{R E}\right\}
$$

Maka persamaan untuk Hausman test sebagai berikut :

$$
\left.\xi_{H}=\left(\widehat{\beta}_{F E}-\widehat{\beta}_{R E}\right)^{\prime}\left[\widehat{V}\left\{\hat{\beta}_{F E}\right\}\right]-\widehat{V}\left\{\hat{\beta}_{R E}\right\}\right]^{-1}\left(\widehat{\beta}_{F E}-\widehat{\beta}_{R E}\right)
$$

dimana; $\widehat{V}_{\mathrm{S}}$ menandakan estimasi covarian matrik yang benar. Hipotesis null secara implisit $\operatorname{plim}\left(\widehat{\beta}_{F E}-\widehat{\beta}_{R E}\right)=0$, statistic $\xi_{H}$ adalah asymptotic distribusi Chi-square dengan derajat bebas $K$, dimana $K$ adalah jumlah elemen di $\beta$.

Secara sederhana Hausman Test membandingkan $H_{0}=$ random effect dan $H_{a}=$ fixed effect. $H_{0}$ ditolak jika prob.Chi-squre lebih kecil dari tingkat kesalahan $(\alpha)$. Hal tersebut menjelaskan model yang tepat untuk regresi data panel adalah model fixed effect (Juanda dan Junaidi, 2012).

\section{HASIL DAN PEMBAHASAN}

Sebelum memilih model mana yang terbaik antara fixed effect dan random effect maka dilakukan hausman test. Hasil hausman test sebagai berikut :

Tabel 3

Hausman Test

\begin{tabular}{lcc}
\hline & Prob.Chi2 & $\alpha$ \\
\hline Sumber : pengolahan data & -0.56 & $5 \%$
\end{tabular}

Sumber : pengolahan data.

Hasil hausman pada Tabel 3 menjelaskan bahwa model yang terbaik pada penelitian ini adalah random effect. Variabel yang digunakan dalam penelitian ini adalah manajemen laba (DA) sebagai variabel dependen, dan variabel independen yang meliputi ukuran komite audit (UKA), proporsi dewan komisaris 
independen (DKI), kepemilikan institusional (KI), kepemilikan manajerial (KM), dan free cash flow (FCF), serta leverage ratio (LEV).

Tabel 4

Statistik Deskriptif

\begin{tabular}{|c|c|c|c|c|c|}
\hline Variable & Obs. & Mean & Std. Dev & Min & $\operatorname{Max}$ \\
\hline DA & 53 & 33.06 & 229.75 & $(2.04)$ & $1,673.30$ \\
\hline UKA & 70 & 3.02 & 0.33 & 2.00 & 4.00 \\
\hline DKI & 71 & 0.39 & 0.94 & 0.13 & 0.66 \\
\hline invsstock & 83 & 36.97 & 29.64 & 3.40 & 100 \\
\hline manjstock & 84 & 71.99 & 20.35 & 15.71 & 96.60 \\
\hline $\mathrm{FCF}$ & 83 & $8.78 \mathrm{E}+10$ & $3.82 \mathrm{E}+11$ & $-7.66 \mathrm{E}+10$ & $1.89 \mathrm{E}+12$ \\
\hline LV & 76 & 0.30 & 0.33 & 0.19 & 1.86 \\
\hline
\end{tabular}

Sumber : Data diolah.

Hasil regresi data panel dengan pendekatan random effect sebagai berikut :

Tabel 5

Random Effect Model

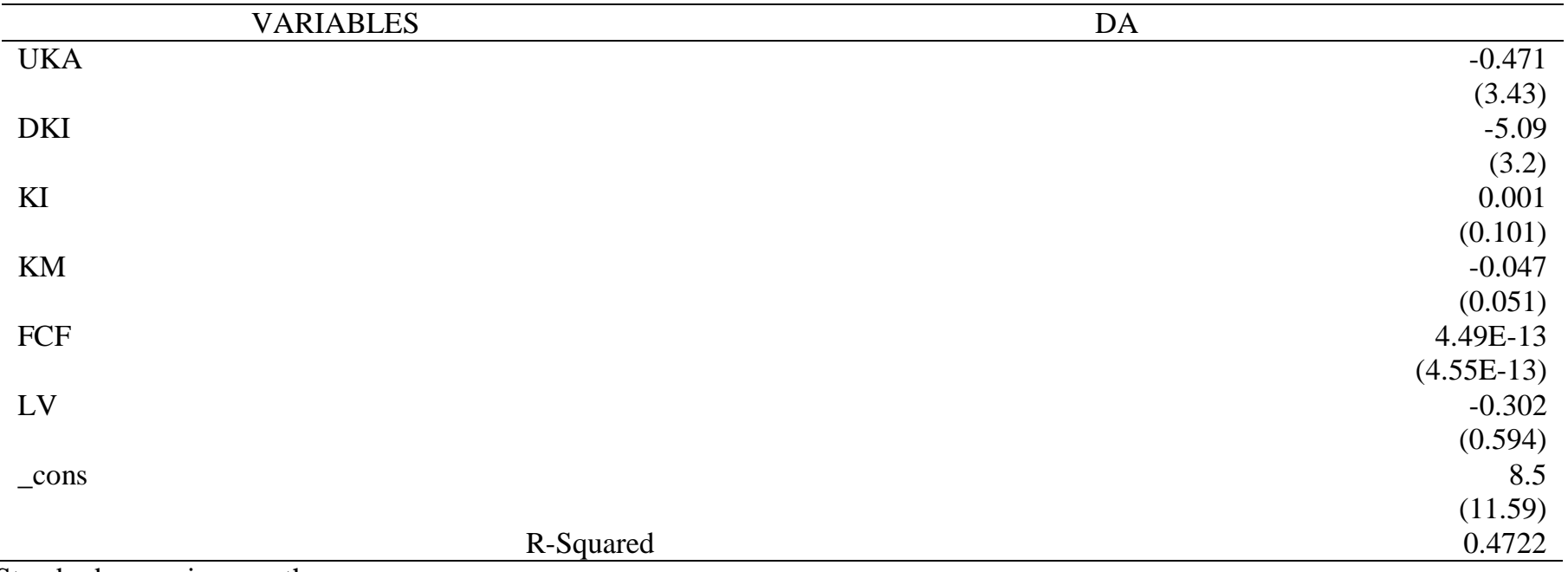

Standard errors in parentheses

$* * * \mathrm{p}<0.01, * * \mathrm{p}<0.05, * \mathrm{p}<0.1$

Sumber : pengolahan data.

Koefisien determinasi model regresi diperoleh dari nilai adjusted R square sebesar 0.4722. Hal ini berarti bahwa variabel independen ukuran komite audit, proporsi dewan komisaris independen, kepemilikan institusional, kepemilikan manajerial, free cash flow, dan leverage ratio mampu menjelaskan perubahan naik turunnya variabel manajemen laba sebesar $47.22 \%$ sedangkan sisanya dipengaruhi oleh faktor lain yang tidak diteliti. Koefisien regresi menunjukkan pengaruh yang berbeda terhadap manajemen laba. Komite audit memiliki koefisien sebesar -0.471 dan tidak signifikan. Artinya, setiap kenaikan 1 anggota komite audit akan menurunkan manajemen laba sebesar 0.47 persen. Proporsi dewan komisaris independen juga memiliki koefisien negatif, yaitu 5.09. Dapat diartikan bahwa setiap kenaikan 1 persen proporsi dewan komisaris independen akan menurunkan manajemen laba sebesar 5.09 persen dan tidak signifikan.

Kepemilikan manajerial dan leverage ratio juga memiliki koefisien negatif. Koefisien dari kepemilikan manajerial sebesar -0.047 dan tidak signifikan, artinya setiap kenaikan kepemilikan manajerial 1 persen maka manajemen laba akan naik sebesar 0.047 persen. Sedangkan leverage ratio memiliki koefisien 0.302 dan tidak signifikan, artinya, setiap kenaikan 1 persen leverage ratio akan menurunkan 0.302 persen manajemen laba. Dua variabel yang memiliki koefisien positif adalah kepemilikan institusional dan free cash flow. Kepemilikan institusional memiliki koefisien sebesar 0.001 dan tidak signifikan, artinya setiap kenaikan kepemilikan institusional 1 persen maka manajemen laba akan naik sebesar 0.001 persen. Sedangkan free cash flow memiliki koefsien sebesar 0.000000000000449 dan tidak signifikan, setiap kenaikan free cash flow akan meningkatkan 0.000000000000449 persen manajemen laba. 


\section{Pengaruh Ukuran Komite Audit Terhadap Manajemen Laba}

Pengaruh negatif dan tidak signifikan ukuran komite audit terhadap manajemen laba pada penelitian ini sesuai dengan penelitian Saleh et al tahun 2007. Regulasi di Indonesia tentang komite audit masih bersifat mandatory. Sifat tersebut mengakibatkan perusahaan membentuk komite audit hanya bertujuan terhindar dari sanksi hukuman. Oleh karena itu, kinerja dari komite audit kurang efektif dan optimal dalam mengembangkan dan menerapkan proses pengawasan untuk meminimalisir praktik manajemen laba.

Menurut Effendi (2009), keberadaan komite audit di perusahaan publik sampai saat ini masih sekedar untuk memenuhi ketentuan pihak regulator (pemerintah) saja. Hal ini ditunjukkan dengan penunjukan anggota komite audit di perusahaan publik yang sebagian besar bukan didasarkan atas kompetensi dan kapabilitas yang memadai, namun lebih didasarkan pada kedekatan dengan dewan komisaris perusahaan. Anggota komite audit semacam ini sulit diharapkan untuk dapat bekerja secara profesional, sehingga besar kecilnya jumlah komite audit di perusahaan tidak akan bisa membatasi terjadinya praktik manajemen laba.

\section{Pengaruh Proporsi Dewan Komisaris Independen Terhadap Manajemen Laba}

Berdasarkan analisis regresi didapat bahwa proporsi dewan komisaris independen berpengaruh negatif dan tidak signifikan terhadap manajemen laba. Hasil penelitian menunjukkan bahwa ukuran dewan komsiaris tidak memiliki kemampuan untuk mengendalikan pihak manajemen sehingga tidak dapat mengurangi earnings management. Hal ini dapat dijelaskan bahwa besar kecilnya dewan komisaris bukanlah menjadi faktor penentu utama dari efektivitas pengawasan terhadap manajemen perusahaan. Akan tetapi efektivitas mekanisme pengendalian tergantung pada nilai, norma dan kepercayaan yang diterima dalam suatu organisasi serta peran dewan komisaris dalam aktivitas pengendalian (monitoring) terhadap manajemen (Jennings, 2005).

Menurut Effendi (2009), dalam kaitannya dengan implementasi $G C G$ di perusahaan, diharapkan bahwa keberadaan komisaris termasuk komisaris independen tidak hanya sebagai pelengkap, karena dalam diri komisaris melekat tanggung jawab secara hukum. Namun dalam praktik yang selama ini terjadi di Indonesia, terdapat kecenderungan bahwa kedudukan direksi biasanya sangat kuat, bahkan ada direksi yang enggan membagi wewenang serta tidak memberikan informasi yang memadai kepada komisaris independen. Selain itu, terdapat kendala yang cukup menghambat kinerja komisaris independen yaitu masih lemahnya kompetensi dan integritas mereka. Hal ini terjadi karena pengangkatan komisaris biasanya harus didasarkan pada penghargaan, hubungan keluarga, atau hubungan dekat lainnya, padahal integritas dan independensi merupakan hal yang fundamental agar GCG dalam perusahaan dapat terwujud secara efektif. Oleh karena itulah dewan komisaris independen di perusahaan masih belum bisa bekerja secara efektif dalam meningkatkan pengawasan terhadap operasional perusahaan dan terbukti tidak berpengaruh serta tidak bisa meminimalisir praktik manajemen laba.

Dewan komisaris independen tidak berpengaruh signifikan terhadap praktik manajemen laba, hal ini dikarenakan komisaris independen ditunjuk oleh pemegang saham mayoritas dalam RUPS sehingga apabila tidak sejalan dengan keputusan pemilik maka perusahaan dapat melakukan penggantian. Jadi, pada praktiknya meskipun komposisi dewan komisaris independen pada perusahaan relatif besar, tetapi mereka tidak bisa benar-benar independen dalam melaksanakan tugas dan pengawasannya karena terbatas oleh peraturan ataupun kebijakan dari pemegang saham mayoritas, sehingga tidak bisa mendorong pelaksanaan good corporate governance secara optimal untuk membatasi praktik manajemen laba.

Semakin tinggi proporsi dewan komisaris, dapat menimbulkan agency problems (masalah keagenan), yaitu dengan makin banyaknya anggota dewan komisaris maka badan ini akan mengalami kesulitan dalam menjalankan perannya, diantaranya kesulitan dalam berkomunikasi dan mengkoordinir kerja dari masingmasing anggota dewan itu sendiri, kesulitan dalam mengawasi dan mengendalikan tindakan dari manajemen, serta kesulitan dalam mengambil keputusan yang berguna bagi perusahaan (Yermack, 1996) dan (Jensen, 1993). Penelitian Zhou dan Chen (2004) menunjukkan bahwa ukuran dewan komisaris di bank komersial tidak berpengaruh terhadap earnings management yang diukur dengan menggunakan loan loss provisions. Hasil penelitian ini juga mendukung penelitian Yu (2006), Murhadi (2009); Oktovianti dan Agustia (2012). 


\section{Pengaruh Kepemilikan Institusional Terhadap Manajemen Laba}

Hasil analisis memperlihatkan bahwa kepemilikan institusional berpengaruh positif dan tidak signfikan terhadap manajemen laba. Hasil penelitian ini mendukung penelitian Guna dan Herawaty (2010) dan Yang et al. (2009), Oktovianti dan Agustia (2012). Tidak signifikan nya kepemilikan institusional terhadap manajemen laba mengindikasikan bahwa tidak adanya kemampuan investor untuk mengendalikan pihak manajemen sehingga tidak dapat mengurangi earnings management. Kepemilikan saham yang besar tersebut seharusnya membuat investor institusional mempunyai kekuatan yang lebih dalam mengontrol kegiatan operasional perusahaan. Tetapi pada kenyataannya, kepemilikan institusional tidak bisa membatasi terjadinya manajemen laba. Hal ini dikarenakan investor institusional tidak berperan sebagai sophisticated investors yang memiliki lebih banyak kemampuan dan kesempatan untuk memonitor dan mendisiplinkan manajer agar lebih terfokus pada nilai perusahaan, serta membatasi kebijakan manajemen dalam melakukan manipulasi laba, melainkan berperan sebagai pemilik sementara yang lebih terfokus pada current earnings (Yang et al., 2009). Transient investors justru akan membuat pihak manajer mengambil kebijakan agar bisa mencapai target laba yang diinginkan para investor. Oleh karena itu, adanya kepemilikan institusional belum tentu akan berdampak pada peningkatan proses pengawasan yang berpengaruh terhadap berkurangnya tindakan manajemen dalam melakukan manajemen laba (Chew dan Gillan, 2009).

\section{Pengaruh Kepemilikan Manajerial Terhadap Manajemen Laba}

Berdasarkan hasil analisis dapat diketahui bahwa variabel kepemilikan manajerial berpengaruh negatif dan tidak signifikan. Penelitian Guna dan Herawaty (2010) serta Pradipta (2011) juga memberikan kesimpulan yang sama. Walaupun kepemilikan manajerial cukup besar diatas 70 persen pada perusahaan yang bergerak di sektor industri barang konsumsi kepemilikan manajerial tidak bisa membatasi terjadinya manajemen laba. Kebijakan mengelola laba dipilih oleh para manajer bertujuan untuk menarik para investor. Salah satu cara yang diambil yaitu dengan meningkatkan laba yang dilaporkan sehingga banyak investor yang tertarik untuk menanamkan modal dan bisa menaikkan harga saham perusahaan. Kegagalan pihak manajemen yang juga merupakan pemilik modal perusahaan dalam meningkatkan kualitas dan proses pelaporan keuangan disebabkan karena presentase manajer yang memiliki saham relatif sangat kecil jika dibandingkan dengan keseluruhan modal yang dimiliki investor umum.

\section{Pengaruh Free Cash Flow Terhadap Manajemen Laba}

Berdasarkan hasil analisis ditemukan bahwa $F C F$ memiliki pengaruh positif dan tidak signifikan. Hasil penelitian yang sama juga ditemukan Ramadhani dkk (2017), Chung et al (2005), dan Kangarluei et al. (2011) dimana FCF berpengaruh positif dan tidak signifikan. Ditambahkan lagi menurut Chung et al (2005) perusahaan dengan arus kas bebas (free cash flow) yang tinggi akan memiliki kesempatan yang lebih besar untuk melakukan manajemen laba, karena perusahaan tersebut terindikasi menghadapi masalah keagenan yang lebih besar. Free Cash Flow perusahaan yang tinggi tanpa adanya pengawasan yang memadai bisa terjadi karena pihak manajer tidak memanfaatkan secara optimal kas yang tersedia secara tepat, atau menggunakannya untuk investasi yang menguntungkan dirinya sendiri. Hal ini berdampak pada peningkatan praktik manajemen laba untuk meningkatkan pelaporan laba, sehingga adanya ketidakefisienan dalam penggunaan arus kas tersebut bisa tertutupi.

\section{Pengaruh Leverage Ratio Terhadap Manajemen Laba}

Hasil regresi menunjukkan leverage ratio berpengaruh negatif dan tidak signifikan terhadap manajemen laba. Hasil analisis tersebut sesuai dengan penelitian Siregar dan Utama (2005) dan Herawaty (2008) yang menyatakan bahwa leverage ratio perusahaan tidak berpengaruh signfikan terhadap praktek manajemen melakukan earnings management. Perusahaan yang mempunyai rasio leverage yang tinggi juga akan memiliki proporsi hutang yang lebih besar dibanding aktivanya. Hal ini mengakibatkan kecenderungan manipulasi dalam bentuk earnings management. Teori keagenan menjelaskan bahwa terdapat agen yang biasanya dianggap sebagai pihak yang ingin memaksimumkan diri sendiri tetapi tetap selalu berusaha memenuhi kontrak. Kontrak yang dimaksud bisa berbentuk kontrak utang. Perusahaan merupakan agen dan kreditur sebagai prinsipal. Semakin dekat perusahaan dengan pelanggaran perjanjian utang yang berbasis akuntansi, bertambah besar kemungkinan manajer perusahaan untuk memilih prosedur akuntansi yang 
memindahkan laba yang dilaporkan dari periode masa datang ke periode saat ini (Watts and Zimmerman, 1986). Hal tersebut dilakukan karena laba bersih yang dilaporkan naik akan mengurangi kemungkinan kegagalan membayar hutang-hutangnya pada masa mendatang (Scott, 2006). Jadi sangat dimungkinkan manajer perusahaan mempengaruhi angka-angka akuntansi pada laporan keuangan, khususnya angka laba bottom line.

\section{SIMPULAN}

Berdasarkan hasil analisis yang telah dijelaskan beberapa yang dapat disimpulkan sebagai berikut :

1. Variabel - variabel Good Corporate Governance $(G C G)$ tidak berpengaruh terhadap praktek manajemen laba. Keberadaan komite audit dan proporsi dewan komisaris di perusahaan publik sampai saat ini masih sekedar untuk memenuhi ketentuan pihak regulator (pemerintah) saja, sehingga besar kecilnya jumlah komite audit dan proporsi dewan komisaris di perusahaan tidak bisa membatasi terjadinya praktik manajemen laba. Kepemilikan institusional tidak berpengaruh terhadap manajemen laba. Hal ini dikarenakan investor institusional tidak berperan sebagai sophisticated investors. Kepemilikan manajerial juga tidak berpengaruh terhadap manajemen laba karena presentase manajer yang memiliki saham relatif sangat kecil jika dibandingkan dengan keseluruhan modal yang dimiliki investor umum.

2. Variabel free cash flow berpengaruh positif dan tidak signifikan terhadap manajemen laba. Hal ini dikarenakan perusahaan dengan arus kas bebas yang tinggi cenderung tidak akan melakukan manajemen laba, karena meskipun tanpa adanya manajemen laba, perusahaan sudah bisa meningkatkan harga sahamnya.

3. Leverage ratio tidak berpengaruh terhadap earnings management. Hasil ini menunjukkan bahwa perusahaan yang mempunyai rasio leverage yang tinggi, berarti proporsi hutangnya lebih tinggi dibandingkan dengan proporsi aktivanya akan cenderung melakukan manipulasi dalam bentuk manajemen laba

\section{DAFTAR PUSTAKA}

Brigham, Eugene, F., \& Houston, J. F., 2010. Dasar-dasar Manajemen Keuangan (Essential of Financial Management). Edisi ke sebelas, buku 1. Terjemahan oleh Ali Akbar Yulianto. Jakarta: Salemba Empat.

Chew, Donald, H., \& Gillan, S. L., 2009. US Corporate Governance. Columbia: Columbia University Press.

Chung, R., Firth, M., \& Kim, J. B., 2005. Earnings Management, Surplus Free Cash Flow, and External Monitoring. Journal of Business Research,58(6), 766-776.

Effendi, Arief., 2009. The Power of Good Corporate Governance Teori dan Implementasi. Jakarta: Salemba Empat.

Ghozali, I. \& Chariri, A., 2007. Teori Akuntansi. Semarang: Badan Penerbit Universitas Diponegoro.

Guna, W. I. \& Herawaty, A., 2010. Pengaruh Mekanisme Good Corporate Governance, Independensi Auditor, Kualitas Audit dan Faktor Lainnya Terhadap Manajemen Laba. Jurnal Bisnis Dan Akuntansi. 12(1): 53-68.

Jennings, M. M., 2005. Conspicuous Governance Failures: Why Sarbanes-Oxley Is not an Ethics Warranty. Corporate Finance Review, 9(5), 41-47.

Jensen, M. C., 1993. The Modern Industrial Revolution, Exit, and The Failure of Internal Control Systems. The Journal of Finance, 48(3), 831-880

Juanda, B., \& Junaidi. 2012. Ekonometrika Deret Waktu Teori Dan Aplikasi. Bogor: IPB Press.

Kangarluei, S.J., Morteza, M., \& Taher, A., 2011. The Investigation And Comparison Of Free Cash Flows In The Firms Listed In Tehran Stock Exchange (Tse) With An Emphasis On Earnings Management. Int. Journal of Economics and Business Modeling, 2(2), 118-1123

Murhadi, Werner R., 2009. Studi Pengaruh Good Corporate Governance Terhadap Praktik Earnings Management pada Perusahaan Terdaftar di PT Bursa Efek Indonesia. Jurnal Manajemen Dan Kewirausahaan, 11(1), 1-10.

Oktovianti, T. \& Agustia, D., 2012. Influence of the Internal Corporate Governance and Leverage Ratio to the Earnings Management. Journal of Basic and Applied, 2(7), 7192-7199 
Ramadhani, F,. dkk., 2017. Pengaruh Capital Intencity Ratio, Free Cash Flow, Kualitas Audit, dan Leverage Terhadap Manajemen Laba pada Perusahaan Manufaktur yang Terdaftar di BEI. Jurnal Ilmiah Akuntansi : Kompartemen Vol. XV No. 2, 98-110.

Scott, William R., 2011. Financial Accounting Theory. Sixth Edition. Canada: Person Prentice Hall.

Siregar dan Utama., 2005. Pengaruh Struktur Kepemilikan, Ukuran Perusahaan, dan Praktek Corporate Governance Terhadap Pengelolaan Laba (Earnings Management). Simposium. Nasional Akuntansi VIII IAI.

Verbeek, Marno., 2008. Text A Guide to Modern Econometrics. Wiley.

Watts, R. L. and Zimmerman, J. L., 1986. Positive Accounting Theory, Engelwood Cliffs, NJ.

Yang, W. S., Loo, S. C., \& Shamser., 2009. The Effect of Board Structure and Institutional Ownership Structure on Earnings Management. International Journal of Economics and Management, 3(2), 332353.

Yermack, D., 1996. Higher Market Valuation of Companies with Small Board of Directors. Journal of Financial Economics. 40, 185-211.

Yu Frank., 2006. Corporate Governance and Earnings Management. Working Paper.

Zhou, Jian \& Chen Ken Y., 2004. Audit Committee, Board Characteristics and Earnings Management by Commercial Banks. Working Paper. 